\title{
Elogio del silencio
}

\author{
Luis Ángel Montes Peral \\ Director del Aula de Teología de UVa. Campus de Palencia \\ Prof. Emérito Estudio Teológico Agustiniano
}

Resumen: Algunos hablan mal del silencio, más por desconocimiento de su valor existencial que por haber hecho una reflexión seria sobre el tema, haberlo asumido en su intimidad y vivenciado en la concreción diaria. Pienso que el silencio, debidamente experimentado y orientado en la propia vida, constituye una de las grandes fuerzas existentes en el interior humano. Aunque parezca contradictorio, el silencio habla, en ocasiones más que la palabra. El auténtico silencio desemboca en las mayores revelaciones, que pueden proporcionar sentido al ser y quehacer de las personas, a sus ansias de verdad, bondad y belleza. No lo dudemos: la verdad, la bondad y la belleza más profundas, que no dejan de transparentar su misterio, pueden encontrarse reflejadas detrás del silencio más profundo. No tengamos miedo entonces al recogimiento interior, ya que puede mostrarnos tesoros insospechados y ofrecérnoslos con la sencillez que solo proporciona la serenidad, la paz del espíritu.

Palabras clave: Trinidad, Silencio, interioridad, misterio, revelación,

Abstract: Some people speak ill of silence, more because of ignorance of its existential value than for having made a serious reflection on the subject, having assumed it in its intimacy and experienced it in the daily concretion. I believe that silence, properly experienced and oriented in one's own life, constitutes one of the great forces present in man's interior. Although it may seem contradictory, silence speaks, at times more than 
words. The true silence opens up to the greatest of revelations, which can provide meaning to the existence and endeavors of men, to their longing for truth, goodness and beauty. Let no one hesitate: the deepest of truth, goodness and beauty, that never cease to make their mystery transparent, can be found reflected behind the deepest of silence. Let us not be then afraid of the inner recollection, for it can show us unsuspected treasures and offer them to us with the simplicity which only serenity, the peace of the spirit, can provide.

Keywords: Trinity, Silence, interiority, mystery, revelation

\section{A favor del silencio}

Dos escritores actuales, una mujer y un hombre, han sentenciado que «escribir es combatir al silencio» ${ }^{1}$. Craso error: al silencio no se le puede considerar como un contrincante, más bien se le acoge como uno de los mejores amigos, portador de sentido y creador de intimidad. Te puede ayudar a transformar tu existencia cotidiana para bien. El silencio, cuando es auténtico, se muestra como uno de los mayores bienes a conservar en nuestro caminar diario en busca de lo trascendente.

El silencio no puede identificarse con el olvido, la inanidad, sino compararse a una mina de oro, de donde se extraen auténticas piedras preciosas. No va contra nada, ni se opone a nadie; bien al contrario, se nos brinda como un valor inmenso, está llamado a ser asumido por cada uno de noso-tros y a compartir su beneficio con los demás. Mediante la palabra el ser humano supera a los demás seres de la naturaleza, pero con el silencio es capaz de situarse por encima de sí mismo hasta alcanzar el Misterio de los misterios.

Pocas cosas tan importantes en la existencia humana como el silencio gozosamente acogido y suficientemente ahondado. No constituye un con-

${ }^{1}$ Cristina SÁnChEZ-ANDRAdE y Alberto ECHEVARRÍA, Escribir un árbol, plantar un hijo y tener un libro. Un diálogo sobre escritura creativa. Triacastela, Madrid 2021. Estoy de acuerdo con lo que la autora mantiene en una entrevista: «Escribir es un modo de interpretar la vida y de aportar esa interpretación al mundo que se vive». Precisamente para conseguir ese objetivo ¡necesitamos silencio, cuanto más prolongado mejor! Ese silencio nos permite sin duda sacar las mejores ideas, que se gestan en nuestro interior en beneficio de los demás. 
trasentido afirmar, que donde mejor resuena el sonido de los vocablos es precisamente en el silencio, convertido en degustación de la sabiduría. Las ideas más brillantes, los pensamientos más acertados, los argumentos más vivos parten del silencio y desembocan en él. La persona incluso puede llegar a expresarse mejor con el silencio que con el lenguaje hablado.

De su interior sale la palabra, nace la escritura y se entabla el diálogo, autentificándose como un bien, que cada uno puede aportar en su apertura hacia los demás. Sin recogimiento en el silencio la condición humana puede llegar a pervertirse, a un hablar por hablar o escribir por escribir, sin decir nada que realmente pueda interesar. Aunque nos parezca sorprendente, el silencio nos cuida y acompaña en momentos de necesidad. Una parte esencial del hombre consiste en saber callar, para luego saber reflexionar y más tarde, saber vivir, siempre aprovechando el sentido de la intimidad.

Sin silencio todo puede convertirse en caótico, degenerar la memoria, perderse los recuerdos; es posible que lo más fundamental quede en el olvido hasta perder lo esencial del discurrir humano. ¿La mediocridad existente hoy en la sociedad, la barbarie que mueve no pocos comportamientos, la mentira tan frecuente en las redes sociales y tan dramática en el ámbito político, no se deberá al abandono que hemos hecho del silencio, habituándonos al estrépito y al ruido, al egoísmo y a la irreflexión? El silencio no nos aísla; al contrario, nos abre de par en par a lo más sublime y humano. No nos aparta del mundo real, sino que nos lleva de bruces a encontrarnos con las mayores realidades materiales y espirituales.

\section{Vivir la interioridad para practicar la exterioridad}

El silencio nos posibilita mirarnos por dentro para luego cambiar por fuera. ¡Cuánto necesitamos que la interioridad nos ayude a transformar la exterioridad! De esta manera podremos guardar equilibrio entre el ser y el quehacer, lo interior y lo exterior, ya que ambas perspectivas se corresponden a las dos caras de la misma moneda, a lo más valioso del tesoro humano, que ofrece su reflejo tanto en lo existente por dentro como por fuera $^{2}$.

\footnotetext{
${ }^{2}$ Pablo D’Ors, Biografía del silencio. Círculo de Lectores, Barcelona 2020; Id, Bio-
} 
Hacemos silencio sobre todo para verificar dos cosas: ver la realidad en su profundidad y escuchar lo que más precisamos oír de ella. Primero observar la realidad, contemplando aquello que tiene de más hondo e intentando serle obediente con la actitud propia de quien busca la honestidad. Y en esa contemplación la realidad básica consiste en la presencia y actuación de la Trinidad. El Padre, el Hijo y el Espíritu Santo actúan en nosotros, no existiendo realidad más alta y honda, más grande y suprema.

Segundo disponernos a la escucha. La Trinidad no solo se encuentra en lo más profundo de nuestro interior, también nos habla a través de la Palabra de los profetas, sabios y poetas de la Sagrada Escritura en su Primer Testamento, pero sobre todo a través de su Hijo en las páginas del Evangelio y en lo que tiene que ver con su obra salvadora testimoniada en el Segundo Testamento. De esta manera seremos obedientes a la realidad y nos encontraremos en la mejor disposición para actuar en consecuencia.

De aquí se derivan preguntas esenciales, que tienen que ver con uno mismo y con los demás. ¿Quién soy yo? ¿Quiénes son mis hermanos los hombres? ¿Qué estoy llamado a hacer? ¿Qué hacer en comunión con mis hermanos? ¿Qué creo, qué espero, qué amo? ¿Qué creen, que esperan, que aman mis semejantes? Podemos encontrar las respuestas más acertadas mediante la actitud de acogernos al silencio interior, para luego salir a la praxis exterior. El silencio puede ser tanto más estimado, cuanto más se convierta en experiencia viva, que abre al Padre, a los hermanos en el Hijo y al mundo bajo la guía del Espíritu.

\section{Silencio y Trinidad}

El silencio no nos paraliza, nos permite caminar con la cabeza alta, levantar los ojos al cielo e implorar la protección de lo alto, ya que el Dios Trino siempre está a nuestro lado y no deja de acompañarnos cada instante. En su origen la Trinidad es silencio y de ese sagrado silencio nació la creación, apareciendo el hombre a su «imagen y semejanza». En ese silencio eterno se gestó el acontecimiento trascendental de que la Palabra se hiciera carne y tomara un cuerpo como el nuestro, aceptando la condición humana. Nada nos asemeja más con el Dios Trino que la bendita ca-

grafía de la luz. Una lectura mística del evangelio. Galaxia Gutenberg, Barcelona 2021. 
pacidad para hacer silencio a nuestro alrededor en apertura hacia la trascendencia y en la posibilidad posterior de hablar con un lenguaje que el Padre, el Hijo y el Espíritu Santo han conferido a su criatura preferida.

Un famoso teólogo alemán se pregunta en su libro póstumo: «¿Habla Dios verdaderamente, cuando "habla"? ¿Es entendible su lenguaje? ¿Habla callando?» ${ }^{3}$. Los tres interrogantes tienen una respuesta positiva, si se explica debidamente su contenido. El Padre «habla» por medio del Hijo Jesucristo, ya que es la Palabra humanada, que da consistencia a las demás palabras y las explica. El Hijo es «entendible» mediante la acción del Espíritu, que viene en ayuda de nuestro espíritu y nos hace comprender la hondura del Evangelio predicado y testimoniado.

El Padre, el Hijo y el Espíritu también hablan callando, cuando aman sin palabras con la fuerza de una entrega incondicional, que se traduce en hechos, que pueden hacerse experiencia viva. ¡Cuánto nos cuesta interpretar el silencio divino! Sin embargo, a la larga podemos entenderlo como un lenguaje de amor, que penetra mucho más eficazmente en nosotros que tanta verborrea como abunda en la actualidad y en realidad no dice nada, aunque pensemos que es trayente, porque viene envuelta en seductor papel de celofán.

Cada verdadero creyente está llamado a explicitar las tres preguntas propuestas en su vida, porque él es quien mejor conoce la hondura que tiene su relación con las Tres Divinas Personas y su capacidad de humanidad, de apertura libre y consciente a ella. Una cosa es particularmente cierta: Solo en el silencio, que luego se hace reflexión y conduce a la acción, descubrimos gozosos la voluntad del Dios Trino y su proyecto de amor sobre cada uno de nosotros. Cuando la Trinidad Santa no se revela en el silencio, no es porque Ella no quiera hacerlo, sino porque algo fundamental le falta al orante, que le impide abrirse a los mejores secretos que se encierran en el misterio trinitario.

Ante la cultura del ruido y el alboroto estamos llamados a contraponer el testimonio del silencio interior para encontrarnos con el Padre, escuchar al Hijo y dejarnos dirigir por el Espíritu Santo. El silencio nos dice que no hubiéramos podido encontrarnos con el Padre si Él, como afirma san Agus-

${ }^{3}$ Klaus Berger, Schweigen. Eine Theologie der Stille. Herder, 2021, Friburgo de Brisgovia. 
tín, no nos hubiera buscado primero ${ }^{4}$. No hubiéramos escuchado al Hijo, si Él antes no nos hubiera hablado en el Evangelio. No hubiéramos acertado con el camino, si el Espíritu no nos hubiera precedido con su inspiración.

Por eso «no digas "no puedo". Di a Dios: "Tú puedes". No digas "sin esto o aquello no puedo vivir". Di a Dios y dilo alto, una vez más, paciente y tenaz: "Solo sin ti no puedo ser" ${ }^{5}$. Únicamente una realidad resulta imprescindible: la presencia y actuación de la Trinidad en cada uno de nosotros. Las Tres Divinas Personas quieren que viva en plenitud, que me ponga en relación directa con ellas y esto es difícil, o mejor dicho, imposible de experimentar sin largos tiempos de silencio orante. Estamos ante secretos mayores, que nos descubre el verdadero silencio, llevándonos a la adoración, la alabanza, la bendición, el agradecimiento y la acción de gracias.

\section{Silencio, Fraternidad y esperanza}

En el silencio trinitario el Padre, el Hijo y el Espíritu Santo nos contemplan como una misma familia con una descendencia común. La Trinidad, que está por encima de nosotros, pero siempre se muestra a favor nuestro, «nos invita a no separarnos nunca del hermano que está junto a nosotros. El más allá de Dios nos remite al más acá del hermano». El Padre en el Hijo por la acción del Espíritu nos conduce una y otra vez a desbordarnos en los hermanos. «Los creyentes estamos llamados a testimoniar su bondad, a mostrar su paternidad mediante la fraternidad ${ }^{6}$. Descubrir extasiados esta experiencia en el silencio, nos hace aún más sensibles a lo humano y fraternal.

Para amar el silencio como hijos y hermanos es preciso gastar tiempo y paciencia en su adquisición. Sentir la quietud que la sensibilidad proporciona en el interior de uno mismo, no significa en modo alguno ensimismarse en lo propio, sino capacidad para llenarse de lo divino y lo humano en calidad filial y condición fraternal. Vivir el silencio capacita para encontrarse con el Padre y los hermanos, vivenciar la filiación y la fraternidad, caminar por las sendas que conducen a la plenitud. En la quietud se saborea más lo trascendente, que nos produce asombro y adoración, elevando el

\footnotetext{
${ }^{4}$ «No te hubiera encontrado si tú no me hubieras buscado primero».

${ }^{5}$ Christian Olding, Christ in der Gegenwart (28, 2021).

${ }^{6}$ Papa Francisco, Ur 06.03.2021.
} 
espíritu sin necesidad de injustificadas acciones físicas. Cuanto más se descubren las realidades importantes, más se precisa esa quietud para ahondar en ellas, de manera que no se pierdan en la simple exterioridad.

El silencio rompe con los convencionalismos, para abrirse a la capacidad de encontrarse con lo último, para poder alcanzar la ultimidad de lo definitivo. Se trata de algo que el mundo no puede proporcionar, pero sí el Espíritu del Padre y del Hijo, que nos abre al amor, la verdad y la belleza. Educar en estos aspectos tan fundamentales para el crecimiento humano constituye la mejor manera de experimentar la esperanza en la existencia concreta de cada día; esperanza a la que nos tiene destinado el Espíritu. El silencio nos posibilita vivir agradecidamente la esperanza en el mundo, de modo que nos lleva a la trascendencia, que nos conduce a la vida eterna definitiva.

No se puede encubrir el silencio bajo la falsa sensación de la acción, que puede ser que no sea más que activismo inútil y servil. La quietud, bien orientada, significa concentración para la auténtica praxis. El activismo sin más dispersa en una actuación ineficaz, que no conduce a ninguna parte. ¡Bienaventurados los que permiten que el Espíritu, amante del silencio, oriente sus pasos y no se dejan llevar por los ruidos y el estrépito, que despistan del auténtico esperar y falsean el camino hacia la salvación última!

\section{Silencio y creación}

Abrir la mirada hacia la naturaleza significa callar y adorar; callar y alabar; callar y bendecir; callar y agradecer; callar y dar gracias. En el mundo se encuentran infinidad de huellas de la Trinidad. De hecho, los seres creados pueden considerarse como un cofre de tesoros, entre los que se encuentra la presencia del Padre, del Hijo y del Espíritu Santo, cuando el silencio nos ayuda a descubrirla y nada impropio nos distrae en ello. Contemplar el cielo, la luna y las estrellas; extasiarse ante el mar, los ríos y las montañas; detenerse en la belleza de un paisaje, admirar la hermosura de una flor; todo ello constituye sin duda un momento privilegiado de admiración, en el que podemos exclamar, de manera semejante al salmista, Trinidad nuestra, ¡qué admirable es tu nombre en todo el universo! (Cf Sal 8,10).

Los animales, los vegetales, las cosas de cualquier tipo son criaturas de la Trinidad, aunque no tienen la capacidad de poder bendecirla; en cambio el hombre callado, sí. Pero el ser humano no se queda en el silencio, ya 
que en su misma entraña se origina la palabra como una explosión de acción y alabanza, de reflexión hablada y diálogo. Del silencio sale la bondad, la verdad y la belleza. Es más, el callar con sentido constituye el camino más directo para encontrar el amor, dar con la verdad y abrirse al resplandor de la hermosura.

Relacionarse en profundidad con la Trinidad consiste en tener experiencia silenciosa de su bondad, digna de ser glorificada mediante la soledad sonora y la plegaria agradecida. Quien desprecia el silencio y pasa la vida parloteando, como si fuera propio de simples el mantenerse callado, cuando hoy resulta más necesario que nunca reflexionar antes de hablar, ya no es capaz de rezar, de agradecer la esperanza y pronto habrá perdido la capacidad para amar y tener una fe viva.

El recogimiento interior representa un bien superior, en el están presentes la reflexión y la acción, la contemplación y sobre todo la inspiración del Espíritu, que nos ha otorgado el Padre por mediación del Hijo Jesucristo. Apreciar la significación del silencio significa ser sensible a lo que la Trinidad puede realizar en nuestra existencia cotidiana, más allá de los sentidos, de lo visible a los ojos, de la percepción de la corporeidad. Arrastra consigo serenidad, para dejar que los pensamientos y sentimientos se hagan uno en la propia persona, más allá de las imágenes que a veces orientan, pero otras veces despistan.

\section{Desenlace: tres realidades decisivas}

El silencio descubre tres grandes realidades, que podemos resumir así:

- El deseo de la Trinidad.

- El sentido del ser y quehacer en el mundo.

- El discernimiento espiritual.

\subsection{El deseo de la Trinidad}

El mejor deseo que el creyente puede experimentar en la puesta en práctica de su fe, tiene que ver con las ansias de la Trinidad. Y este inmenso deseo solo resulta posible mediante la aceptación de la gracia trinitaria y 
la inmersión continuada en el silencio ${ }^{7}$. Disponiendo el cuerpo y el espíritu para la apetencia del Padre, del Hijo y del Espíritu, la persona mediante la reflexión interior es capaz de llegar a las mayores grandezas, que siempre obrarán en la humildad de su intimidad. Entonces podrá exclamar en medio de un gran regocijo: la Trinidad es mía y toda Ella se vuelca en mí. Cuando esa apetencia se hace fuerte, la persona está salvada, necesariamente queda renovada por dentro. No se trata tanto de pensar con la cabeza, como dejar que palpite el corazón en un afecto incesante, que ojalá se haga cotidiano.

Las Tres Divinas Personas no se cansan de nosotros, aunque desgraciadamente nosotros no las tengamos siempre en cuenta, cuando más las necesitamos. Es posible que incluso lleguemos a olvidarlas, aunque sea en momentos de especial dificultad. Recuperar este deseo, cuando languidece, constituye una gracia más, que todos podemos pedir cada día al Espíritu. Él es capaz de convertirnos de nuevo en un oasis de paz, en el que sea posible el encuentro vivo con el Dios Trino en la serenidad, estableciendo nuevos vínculos de amor, que nos hagan más y más felices. ¡Rodéate gustoso de la generosidad de la Trinidad, acércate a su belleza, que te hará mucho bien!

Hace muy poco escribí: «En el momento presente, valoro mucho el silencio y la contemplación ${ }^{8}$. Esta constatación se ha intensificado en mí en estos momentos. Cada vez me percato más de que la Trinidad nos habla en el silencio, cuando quiere ser acogida y amada, entendida y valorada en lo más íntimo de nuestro yo. De todas las realidades religiosas que los creyentes indagamos en nuestro interior, la experiencia de la Trinidad es con mucho la más grande de todas, la que nos aporta mayor tranquilidad y nos proporciona una especial felicidad, adquiriendo nuestra existencia entera un aroma muy especial, que se percibe en el exterior.

Indagando en un pensamiento del Maestro Eckhart podemos afirmar que quien se deja poseer verdaderamente por la Trinidad percibe su pre-

${ }^{7}$ Simone WeIL afirma que no es nuestro deseo el que alcanza a Dios, es la propia Trinidad, «quien desciende a nuestra humanidad para henchir de plenitud nuestro deseo. Mientras tanto nuestro deseo es atención, vigilancia, resiliencia, fidelidad y confianza» (José Tolentino MendoçA, Elogio de la sed [Sal Terrae Maliaño $\left.{ }^{42020]} 54\right)$.

${ }^{8}$ Luis Ángel Montes Peral, Conversión a la fe. Pliego Vida Nueva (13-19 de marzo de 2021,30). 
sencia y actuación en todos los lugares, en la calle, en las plazas, en cualquier sitio, porque el silencio se la está mostrando más que las palabras por acertadas que sean. El Dios Trino resplandece para él en la multiplicidad de las cosas: porque todas ellas despiden el olor de las Tres Divinas Personas. La Trinidad nos contempla cada momento. ¡Qué bueno sería que cada uno de nosotros «viera» al Padre, sintiera al Hijo y experimentara al Espíritu Santo, al menos alguna vez durante el día con los ojos, la vivencia de la fe, la presencia del otro y la mirada del silencio!

\subsection{El sentido del ser y quehacer en el mundo}

El hombre no está solo, está con otros y vive con ellos en el mundo. ¿Estamos en el mejor de los mundos? o, por lo contrario: ¿nuestro mundo es un despojo? Hay opiniones para las dos posiciones: El filósofo optimista Gottfried Wilhelm LEIBNIz (1646-1716) afirmó en su día: «Dios no hubiera creado el mundo, si no fuera entre todos los posibles el mejor»: Gott hätte die Welt nicht erschaffen, wenn sie nicht unter allen möglichen die beste wäre. Emil M. CIORAN ${ }^{9}$, un antihumanista de un pesimismo radical, mantiene la opinión contraria, llegando a afirmar de forma blasfema, que no podemos tan siquiera imaginar un mundo peor al que tenemos. Si Dios lo hubiera creado podemos considerarlo como un chapucero, incluso habría que molerlo a palos.

Con la Sagrada Escritura en la mano pienso que Dios creó el mundo bueno (Gn 1,9.12.18.21.25.31), para el bienestar humano. Todo lo que ha creado y cada instante crea se identifica con la bondad. Así lo afirma con insistencia el relato del primer capítulo del Génesis, uno de los más conocidos y afirmados en la literatura universal. Estamos entonces en un mundo, que merece la pena ser acogido con gozo, transformado para bien y valorado para el presente y futuro de la humanidad ( $\mathrm{Gn} 1,28)$. Todas las personas estamos llamadas a perfeccionarlo con nuestra imprescindible colaboración. Si nos empeñamos en destruirlo, podemos convertir la vida humana en un infierno.

Pero la Trinidad no ha deseado un futuro así para el mundo y para los hombres. Cada instante nos está mostrando los problemas existentes aquí y ahora, en los que debemos prestar atención y tratar de solucionar

\footnotetext{
${ }^{9}$ El aciago demiurgo. Taurus, Madrid 2000.
} 
con la ayuda de la gracia divina. Hay mucho sufrimiento injusto, que estamos llamados a extirpar. Cantidades ingentes de injusticias, que no debiéramos soportar, si valoramos el amor trinitario. Personas privadas de dignidad y derechos fundamentales, que claman al cielo y nos urgen al esfuerzo continuado, si tenemos buena voluntad. Cuando el silencio es $\mathrm{cre-}$ ativo y no resiste el mal, nos permite descubrir lo que falsea al mundo y obrar en consecuencia para que sea mejor.

Está claro que la Trinidad hizo el mundo bueno y quiere que los hombres contribuyamos a transformarlo y perfeccionarlo, siempre en beneficio de todos, no de unos pocos. Somos las manos y el cuerpo del Padre, del Hijo y del Espíritu Santo y esto nos tiene que llenar de alegría, pero también de responsabilidad. El ser y el quehacer de cada uno encuentra sentido cuando se esfuerza por hacer de él su ciudad, su casa y su hogar en comunión con los demás. Reflexionar sobre ello en silencio, para luego actuar de acuerdo con los designios divinos, puede ampliar convenientemente la mirada de nuestro ser y quehacer y hacernos más felices en compañía de los otros. Echar a perder el mundo, es la manera más eficaz de perdernos nosotros mismos, porque hemos sido infieles al plan divino de salvación.

\subsection{El discernimiento espiritual}

El silencio nos ayuda a discernir lo que estamos llamados a hacer en cada momento de nuestra vida y hacerlo como hijos y hermanos. Hijos del Padre en el Hijo por el Espíritu y hermanos en el Hermano Mayor, que se hizo uno de los nuestros, para que nosotros nos pudiéramos convertir en verdaderos hijos del Padre mediante la acción del Espíritu. Discernir bien nos ayuda como nada a vivir de acuerdo con lo que nos dicta nuestra conciencia, de modo que no haya en nosotros desdoblamientos interiores, diferencias inadecuadas y caminos extraviados sino una visión clara y precisa de lo que somos y hacemos en comunión con la Trinidad, nuestros semejantes y el mundo.

El discernimiento interior nos proporciona el auténtico conocimiento de la Trinidad, de la persona humana y del mundo. Trata de responder a estas preguntas trascendentales: ¿Quién es la Trinidad? ¿Quién es el hombre? ¿Qué cosa es el mundo? ¡Ojalá que en nuestra vida logremos responder a estas tres cuestiones cruciales con la competencia, rigurosidad y 
verdad, que necesitamos mediante un auténtico discernimiento interior, aceptado en el silencio de una meditación debidamente orientada!

El discernimiento interior nos capacita para descubrir con perspicacia lo que está sucediendo a nuestro alrededor en el momento concreto por el que pasamos. Desde hace tiempo no vivimos como debiéramos hacerlo, «de acuerdo con la sensibilidad que hay que tener en relación con la naturaleza, con el mundo donde estamos. (La pandemia) ha sido una seria llamada de atención. No lo estamos haciendo bien, consumimos demasiado, ensuciamos demasiado, matamos demasiado nuestras especies» ${ }^{10}$.

Advertidos por los científicos más prestigiosos, uno de los mayores problemas actuales consiste en el cambio de clima, que tenemos que soportar casi cada día, sobre todo en algunas partes concretas del globo terráqueo. Los signos al respecto resultan bien alarmantes, pero no parece que estemos dispuestos a cambiar, llevados por una inconsciencia pasmosa, que puede tener efectos desastrosos. La degeneración del medio ambiente prosigue sin que hagamos nada verdaderamente eficaz para evitarlo a pesar de las serias advertencias realizadas por instancias bien competentes. Nos conformamos con palabras, palabras, palabras. ¡Y la situación descrita se ceba sobre todo en las personas más pobres, débiles y necesitadas!

El verdadero discernimiento interior nos lleva a observar los comportamientos humanos y buscar el modo concreto de transformarlos para bien. Desgraciadamente existe demasiada miseria moral y no escasea -duele decirlo- una podredumbre social que asusta, que no nos permite descubrir dónde se encuentran las soluciones precisas a los auténticos problemas del aquí y ahora. Basta con acercarse a las redes sociales y observar el comportamiento de las masas, para comprobar que algunos han perdido la dignidad, no saben lo que significa la decencia, obrando con un descaro increíble del que no se sonrojan sino se vanaglorían. Y mientras tanto el mundo se desliza hacia posiciones peligrosas.

Esto no quiere decir que nuestros tiempos sean peores que los anteriores. Pero sí que las intransigencias, los enfrentamientos ideológicos, la agresividad sin matices, los extremismos fundamentalistas, las miserias de todo tipo se propagan con más celeridad que antes y llegan a las masas

\footnotetext{
${ }^{10}$ Antonio LóPeZ, El Mundo (10.07.2001) Entrevista.
} 
mucho más fácilmente que en otras épocas. Necesitamos otra educación, otros criterios vitales, otra orientación política, dejar a un lado la creciente postverdad, trabajar más por la justicia y la equidad, no buscar a toda costa el tener, el placer, el poder, la mera apariencia del figurar.

¿Resulta pesimista afirmar que en el presente no funcionan bien las relaciones entre las personas? ¿La Iglesia en su conjunto está contribuyendo a configurar sociedades más humanas, más respetuosas con el medio ambiente, más austeras, en definitiva más fraternales? ¿Formamos comunidades testificantes de hijos y hermanos, que constituyan un revulsivo en nuestras sociedades? Preguntas todas ellas relevantes, que no nos queda más remedio que hacernos y procurar responderlas con la mayor rigurosidad posible y de modo muy especial con la conveniente eficacia. Después de un buen discernimiento, la dimensión interior necesita reflejarse en un mundo exterior bien dispuesto. Y al revés, también.

Todo ello solo puede conseguirse, cuando prestamos obediencia a la realidad, escucha de la Palabra de Dios, capacidad de aguante, que nos haga resistentes a las banalidades, infamias, barbaries, como hoy se extienden por doquier. Hay actuaciones que de ninguna manera se pueden justificar y soportar, aunque todas las personas tienen derecho a pensar y sentir conforme a su sensibilidad vital. Discernir las situaciones personales, los comportamientos comunitarios, los fenómenos sociales y saberlos aplicar en cada momento concreto, constituye una de las mayores gracias, que puede hacer más llevadora nuestra existencia con recursos espirituales suficientes.

\section{Ser en el Silencio del Amor Trinitario}

Donde mejor me encuentro es asentado en el silencio con la Trinidad en el centro.

Cuando dejo que me poseáis,

Padre, Hijo y Espíritu Santo, sin restricción alguna, situándome bajo vuestro amparo, 
sostenido tan solo por vuestro Amor, que me lleva a entregarme a los pobres, enfermos y pecadores.

Tú, Padre, eres el Amante, Tú, Hijo, el Amado, y Tú, Espíritu Santo, el Amor.

Amante, Amado y Amor sois para mí, ávido de cercanía sobre todo en momentos de soledad.

Enseñadme a no producir dolor con mi arrogancia e impaciencia.

Siempre habéis sido amor para todos y así lo queréis seguir siendo con cada uno.

¡Cuánto necesitamos vuestra acogida amorosa en el núcleo mismo de la pobre existencia humana!

Trabajáis con mi carne y huesos con la totalidad de mi cuerpo y mi espíritu y más allá de mis muchos defectos.

Me queréis íntegro, perseverante y feliz, aunque preparado para aceptar el sufrimiento, que no deja de llegar cuando menos lo esperas.

Me consuela la compasión que tenéis con nosotros,

la misericordia que nos alcanza a todos, aunque no logremos calibrar sus consecuencias porque el egoísmo nos lo impide.

Sé que no os apartáis de mí, no salís de mi interior, queréis estar en lo hondo de mi corazón

y yo quiero con todo mi ser que mi existencia sea así, todo vuestra, solo vuestra, nada más que vuestra. Cuánto deseo sentir vuestra presencia bienhechora, ser consciente de la generosidad que me dispensáis. 
En realidad nos la dispensáis a todos sin excepción, porque vuestro amor alcanza siempre a cada persona aunque en ocasiones nos cueste comprenderlo y vivirlo.

Necesito cada día reconocer vuestra gratuidad, unirme mejor al mundo que habitamos, intensificar las deficientes relaciones humanas y espirituales.

El silencio interior nos permite abrazar el misterio. Un silencio a tiempo puede superar cualquier elocuencia.

No hacéis otra cosa que amar a los hombres, Padre, tener providencia del mundo y sus cosas, sin rechazar a nadie, acogiendo a todos a cada uno de los que habéis dado la vida y amáis conforme a vuestros santos propósitos, descubiertos en el Evangelio por el Hijo y presencializados para todos por la acción del Espíritu. 